\title{
PANORAMA DA DENGUE NA REGIÃO SUL DO BRASIL DE 2001 A 2017*
}

\author{
Andréia Dalla Vecchia', Vilma Beltrame², Fernanda Maurer D’ Agostini ${ }^{3}$
}

\begin{abstract}
Objetivo: inventariar casos notificados por dengue clássica e óbitos na região Sul do Brasil entre 2001 e 2017. Método: estudo descritivo-retrospectivo a partir de dados secundários do DATASUS/SINAN e das Secretarias de Saúde, analisados através de estatística descritiva. Resultados: observou-se aumento dos casos nos três estados: Paraná (PR) elevou casos autóctones para 94\% nos últimos quatro anos, Santa Catarina (SC) para 95\%, e Rio Grande do Sul (RS) para 83\%, respectivamente, em 2015 e 2016. Observou-se crescente aumento de óbitos por dengue hemorrágica, principalmente no PR; em 2016, o primeiro óbito em SC; e aumento nos últimos dois anos no RS, mais de $90 \%$ em adultos. Conclusão: a região requer atenção dos órgãos de saúde, devido ao aumento de casos e óbitos por dengue, embora apresente a menor incidência da doença do país. Este estudo contribuiu para o conhecimento do cenário atual e da evolução da dengue na região Sul do Brasil.
\end{abstract}

DESCRITORES: Notificação de doenças; Mortalidade; Morbidade; Epidemias; Arbovírus.

\section{AN OVERVIEW OF DENGUE IN THE SOUTHERN REGION OF BRAZIL FROM 2001 TO 2017*}

\begin{abstract}
Objective: To record cases reported as classical dengue fever and deaths in the southern region of Brazil between 2001 and 2017. Method: Descriptiveretrospective study using secondary data from DATASUS/ SINAN and State Departments, analyzed through descriptive statistics. Results: An increase in the percentage of cases of the disease in the three states was observed in the three Brazilian southern states: in Paraná (PR) the percentage of autochthonous cases reached 94\% in the last four years; in Santa Catarina (SC), the percentage was 95\%, and in Rio Grande do Sul (RS), 83\%, respectively, in 2015 and 2016. There was an increase in the number of deaths by severe dengue (dengue hemorrhagic fever), mainly in PR; in 2016, the first death caused by dengue was observed in SC; and an increase of more than $90 \%$ in the cases of dengue among adults in the last two years in Rio Grande do Sul. Conclusion: Despite the fact the Southern region of Brazil has the lowest incidence of dengue, special attention should be paid by health agencies to the situation in the southern states due to the increase in the number of cases and deaths caused by dengue.
\end{abstract}

KEYWORDS: Disease reporting; Mortality; Morbidity; Epidemics; Arbovirus.

\section{PANORAMA DE LA DENGUE EN LA REGIÓN SUR DE BRASIL DE 2001 A 2017}

Objetivo: inventariar casos notificados por dengue clásica y óbitos en la región Sur de Brasil entre 2001 y 2017. Método: estudio descriptivo retrospectivo con base en datos secundarios del DATASUS/SINAN y de las Secretarías de Salud, analizados por medio de estadística descriptiva. Resultados: se observó crecimiento de los casos en los tres estados: Paraná (PR) tuvo elevación de casos autóctonos para 94\% en los últimos cuatro años, Santa Catarina (SC) para 95\%, y Rio Grande do Sul (RS) para 83\%, respectivamente, en 2015 y 2016. Se observó todavía creciente aumento de óbitos por dengue hemorrágico, principalmente en PR; en 2016; el primero óbito en SC; y crecimiento en los últimos dos años en RS, más de 90\% en adultos. Conclusión: la región necesita atención de los organismos de salud, a causa del crecimiento de casos y óbitos por dengue, a pesar de presentar la menor incidencia de la enfermedad del país. Este estudio contribuyó para el conocimiento del escenario actual y de la evolución de la dengue en la región Sur de Brasil.

DESCRIPTORES: Notificación de enfermedades; Mortalidad; Morbilidad; Epidemias; Arbovirus.

\footnotetext{
*Artigo produzido durante realização de estágio pós-doutoral em conjunto com docentes do Programa de Mestrado em Biociências e Saúde da Universidade do Oeste de Santa Catarina(UNOESC). Joaçaba, SC, Brasil.

'Bióloga. Doutora em Qualidade Ambiental. Bolsista pós-doutoral (PNPD) do Programa de Mestrado em Biociências e Saúde da Universidade do Oeste de Santa Catarina. Joaçaba, SC, Brasil.

${ }^{2}$ Enfermeira. Doutora em Gerontologia Biomédica. Docente do Programa de Mestrado em Biociências e Saúde da Universidade do Oeste de Santa Catarina. Joaçaba, SC, Brasil.

${ }^{3}$ Bióloga. Doutora em Zoologia. Docente e pesquisadora do Programa de Mestrado em Biociências e Saúde da Universidade do Oeste de Santa Catarina. Joaçaba, SC, Brasil.
}

Autor Correspondente:

Andréia Dalla Vecchia.

Universidade do Oeste de Santa Catarina(UNOESC).

Rua Getúlio Vargas, 2125 - 89600-000. Bairro Flor da Serra, Joaçaba, SC, Brasil.

E-mail: andreiavecchia@gmail.com.
Recebido: 07/07/2017

Finalizado: 15/01/2018 


\section{INTRODUÇÃO}

A dengue é uma doença viral transmitida por mosquitos da família Culicidae, de grande importância em saúde pública. O vírus da dengue (DENV) é constituído de genoma RNA, cadeia simples, e 4 sorotipos distintos (DENV 1, 2, 3 e 4) pertencentes ao gênero Flavivirus e à família Flaviviridae. ${ }^{(1)} \mathrm{A}$ transmissão do vírus ocorre exclusivamente pela picada da fêmea do mosquito Aedes, principalmente da espécie Aedes Aegypti infectada. Pode causar doença febril com sintomas que surgem entre 3 e 14 dias após a picada. A infecção ocasiona doença de amplo espectro clínico, variando desde assintomática, infecções por febre clássica da dengue (FD), até casos graves de febre hemorrágica da dengue (FHD), podendo evoluir para óbito. ${ }^{(1)}$

Até o momento, não há medicamento específico para tratar a dengue, ${ }^{(2)}$ e esta vem emergindo como uma das doenças mais infecciosas do século $X X I,{ }^{(1,3)}$ cerca de três vezes maior do que o estimado pela Organização Mundial da Saúde (OMS). Sua transmissão é ubíqua ao longo dos trópicos, com as maiores zonas de risco nas Américas e na Ásia. ${ }^{(4)}$

A crescente ameaça global de surtos de dengue requer atenção na gestão eficaz destes eventos. (2) Segundo a OMS, 50 milhões de pessoas são infectadas pelo vírus a cada ano e cerca de 1/3 da população mundial vive em áreas de risco. ${ }^{(1)}$ Estimativas apontam elevado número de casos no Brasil, contribuindo com maior número nas Américas (39\%), aproximando-se de 2,1 milhões de casos, no período de 2000 a $2007 .{ }^{(5)}$

No Brasil, os primeiros relatos ocorreram no final do século XIX e início do século XX nas cidades de Curitiba (PR) e Niterói (RJ). No início do século XX, o mosquito já era um problema de saúde, mas não decorrente da dengue e sim preocupações com transmissão da febre amarela. Em 1955 o A. aegypti foi erradicado, mas em 1960 ocorreu a reintrodução do vetor no território nacional. ${ }^{(6)} \mathrm{A}$ primeira ocorrência de surto de dengue no Brasil ocorreu na década de 1980, em Boa Vista (Roraima), onde os sorotipos DEN-1 e DEN-4 foram isolados. ${ }^{(7)}$ Em 1986 houve epidemias no Rio de Janeiro (RJ) e em algumas capitais do nordeste. Atualmente, o vetor e a dengue são encontrados em todos os estados brasileiros. ${ }^{(6,8)}$

As condições climáticas, como elevada precipitação, clima quente e úmido em grande parte do território nacional, favorecem a proliferação e distribuição de culicídeos, insetos vetores que são determinantes para a manutenção do complexo ciclo de infecção dos arbovírus e variação da incidência de casos de dengue, ${ }^{(8-9)}$ embora a região sul seja caracterizada pela ocorrência de períodos alternados de clima frio e moderado. Casos de dengue têm sido registrados em populações urbanas, onde a alta densidade demográfica e a curta distância para o voo do vetor são condições favoráveis para a transmissão viral. ${ }^{(10)}$

Assim, este estudo objetivou identificar número de casos notificados e óbitos por dengue hemorrágica, ocorridos anualmente nos estados do sul do Brasil (PR, SC e RS) no período de janeiro de 2001 a novembro de 2017, tendo em vista que a região sul tem apresentado (estudo de 2002 a 2012) a menor taxa de incidência da doença em comparação com outras regiões do país. ${ }^{(11)}$

\section{- MÉTODO}

Estudo descritivo-retrospectivo, a partir de dados secundários obtidos de registros de notificação de casos de dengue clássica e óbitos por dengue hemorrágica, para as três unidades da federação da região sul do Brasil, PR, SC e RS.

As informações foram coletadas no período de dezembro de 2016 a fevereiro de 2017 e atualizadas em novembro de 2017. Obtiveram-se dados para dengue clássica através da pesquisa, usando código internacional de doença (CID A90), e para óbito por dengue hemorrágica devido ao vírus da dengue (CID A91).

No período de 2001 a 2016 a informação do número total de casos de dengue clássica anual foi obtida a partir da situação epidemiológica, planilha descrita "Casos de Dengue. Brasil, Grandes Regiões 
e Unidades Federadas, 1990 a 2016" disponibilizada no portal de saúde SUS, Ministério da Saúde (SINAN: Sistema de informação de agravos de notificação), o qual informa o número total de casos de dengue em todo país. ${ }^{(12-13)}$

Para o ano de 2017, o número de notificações para dengue clássica foi extraído de boletins epidemiológicos disponíveis na secretaria de saúde de cada estado, ${ }^{(14-16)}$ devido à falta de dados atualizados no portal de saúde SUS.(12) Dados complementares como gênero (masculino e feminino), faixa etária (agrupadas: < 1 ano; 1 a 4 anos; 5 a 19 anos; 20 a 59 anos; > 60 anos) e número de casos autóctones foram extraídos da base do DATASUS (Departamento de Informática do Sistema Único de Saúde - Informações de Saúde TABNET, epidemiológicas e morbidades), no qual coletou-se a partir da opção "Doenças e Agravos de Notificação SINAN, 2001 a 2006 e 2007 em diante, no qual disponibiliza informação até o ano 2012..$^{(13)}$

Dados não contemplados na base anteriormente citada foram obtidos em boletins epidemiológicos, bem como em informações do site da Secretaria de Saúde de cada estado. ${ }^{(14-16)}$ Não foi possível estimar o número de casos autóctones para o ano de 2017 devido à insuficiência de informações. Para ambas as situações de casos de dengue clássica e registro de óbitos, pesquisou-se tendo como base o requisito por residência.

O número de casos de óbitos por dengue hemorrágica foi extraído da base DATASUS - Tecnologia da Informação a Serviço do SUS ${ }^{(17)}$, que disponibiliza informações até o ano de 2015. Registros recentes (2016 até novembro de 2017) foram obtidos em site específico da Secretaria de Saúde de cada estado, explorando a opção TABNET ou em boletins epidemiológicos, ${ }^{(14-16)}$ dos quais foram extraídos, armazenados e analisados utilizando planilhas de Excel. Organizou-se e analisaram-se as variáveis: estado (PR, SC e RS), período anual, faixa etária, gênero, casos autóctones, dengue clássica e óbito por dengue. Com base na quantificação para cada conjunto de variáveis obtiveram-se número absoluto e percentuais correspondentes.

Em se tratando de aspectos éticos, o estudo foi realizado a partir de dados secundários, oriundos de sites de domínio público, e não envolveu questões e autorização de comitês de ética.

\section{RESULTADOS}

\section{Dengue clássica e óbitos decorrentes do vírus da dengue}

Resultados para os casos de dengue clássica estão expressos nas Figuras 1, 2 e 3 e retratam o número de casos notificados de dengue e número de casos autóctones para os três estados do sul do Brasil. Avaliou-se a situação de casos autóctones a partir do ano de 2007, tendo em vista que anterior a isso não há registro na base consultada.

Tratando-se do estado do PR (Fig. 1), em média 71\% dos registros foram considerados autóctones (transmissão dentro do estado de 2007 a 2012). Porém, nos últimos 4 anos (ano de 2017 não incluso) os dados representam $94 \%$. 


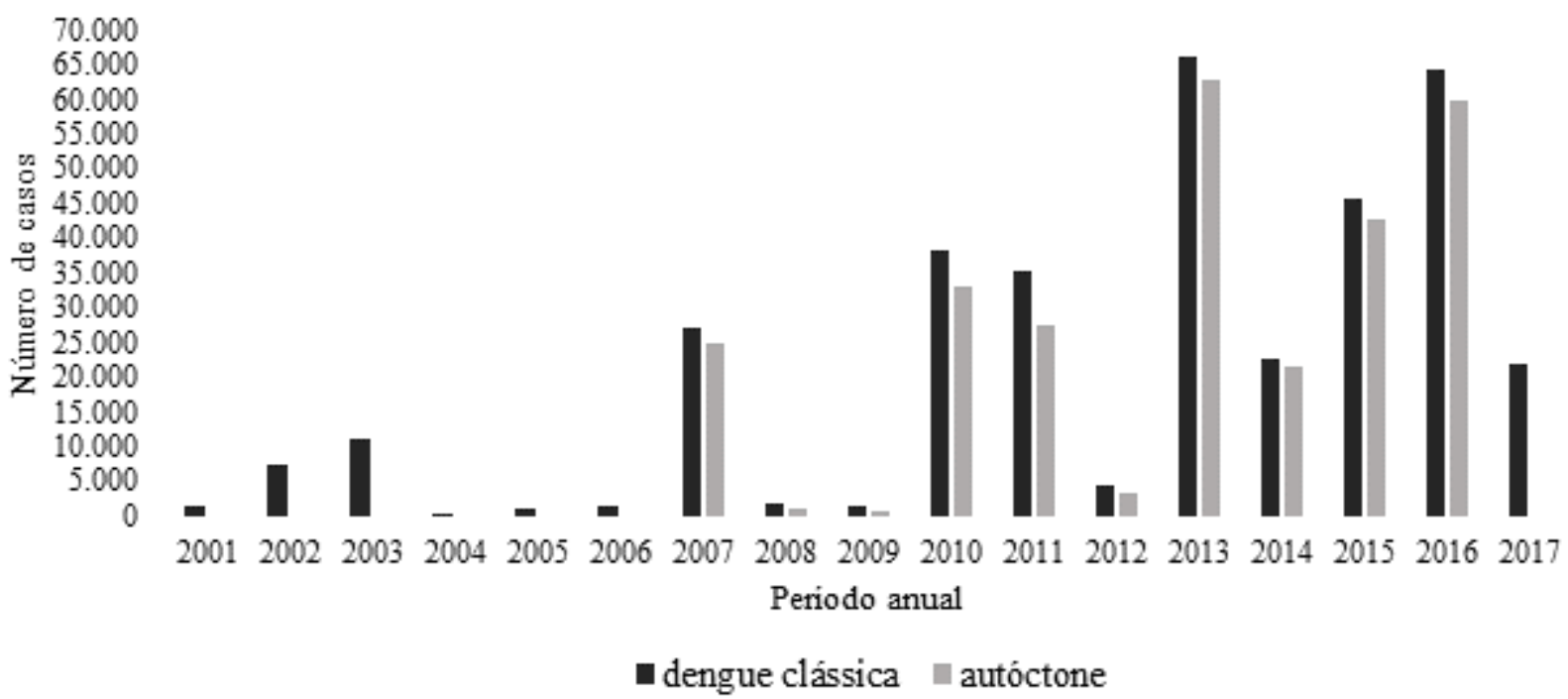

Figura 1 - Número total de casos notificados de dengue clássica e registros autóctones no PR entre 2001 e novembro de 2017. Paraná, Brasil, 2017

Para o estado de SC (Fig. 2), no período de 2007 a 2014, os dados revelam baixo número de casos autóctones (média de 4\%). No entanto, pode-se verificar um aumento nos últimos dois anos, em que esta média elevou para 95\% (não incluso ano de 2017). Observou-se também aumento de casos principalmente em 2015 e 2016, que se aproximou de 5.000 casos anual, enquanto nenhum período anual anterior ultrapassou 300 casos.

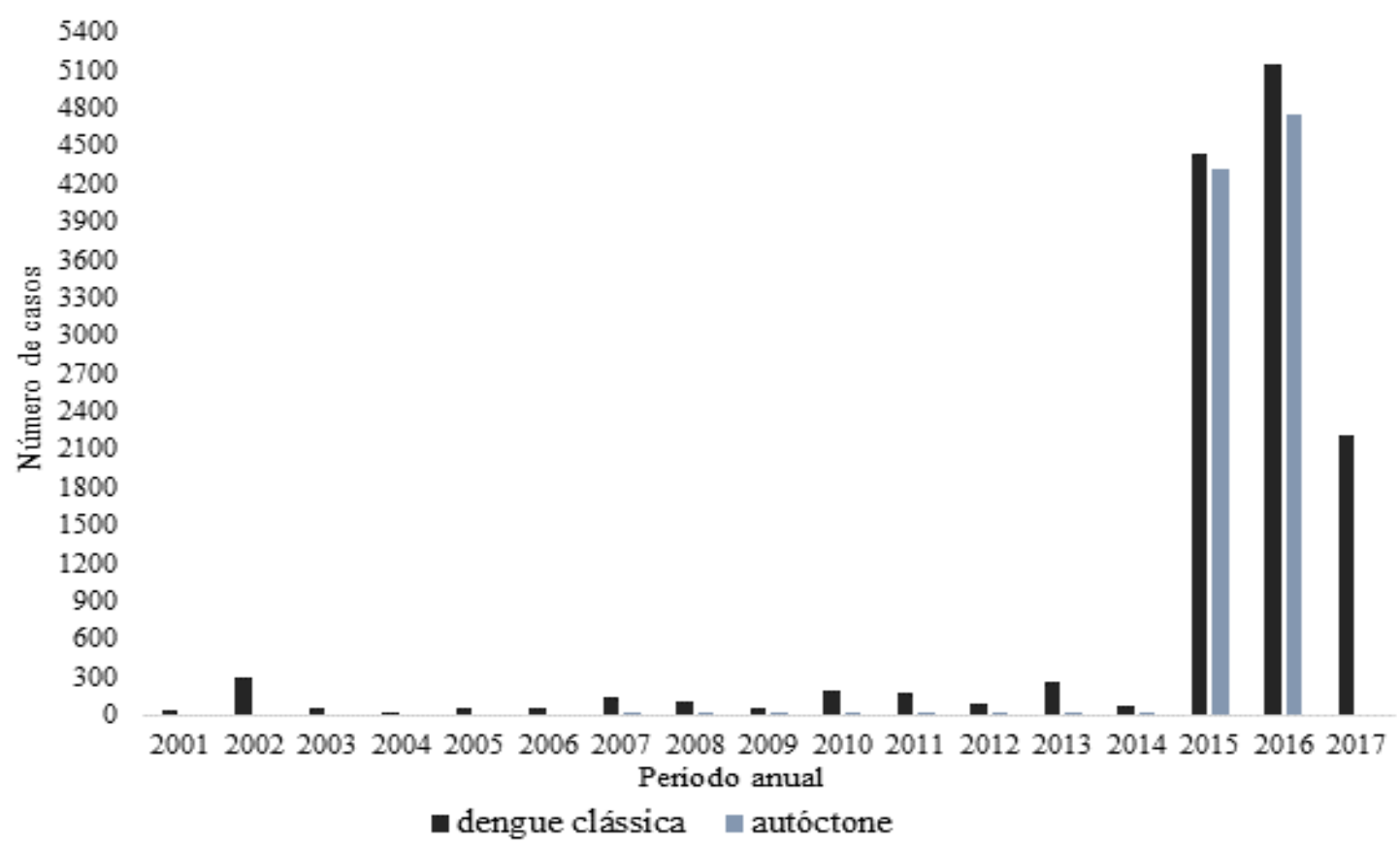

Figura 2 - Número total de casos notificados de dengue clássica e registros autóctones em SC entre 2001 e novembro de 2017. Santa Catarina, Brasil, 2017

No RS (Fig. 3), em média (período 2007 a 2014) a taxa de casos autóctones atingiu 43\% e nos últimos dois anos elevou a taxa de autóctone para 83\% (exceto 2017). O maior número de casos de dengue foi em 2010 com mais de 3.500, e em 2016 com 3.195 notificações. 


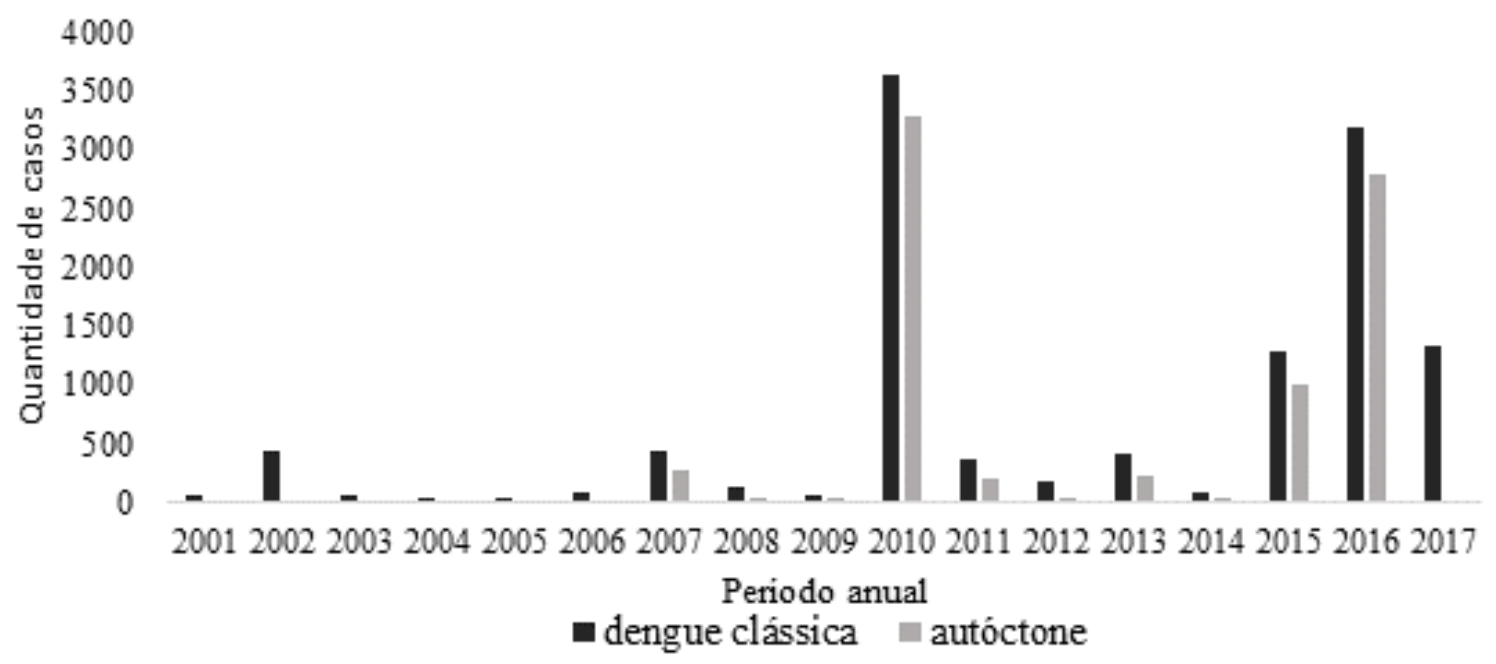

Figura 3 - Número total de casos notificados de dengue clássica e registros autóctones no RS entre janeiro de 2001 e outubro de 2017. Rio Grande do Sul, Brasil, 2017

A Figura 4 representa o acometimento por dengue clássica nas diferentes faixas etárias ocorridos nos três estados. Em 80\% dos casos indivíduos adultos foram afetados, e a faixa etária entre 20 e 59 anos apresentou a maior taxa de adoecimento por dengue clássica (70\%). Em contrapartida, a menor faixa atingida são crianças com idade inferior a 1 ano (1\%).

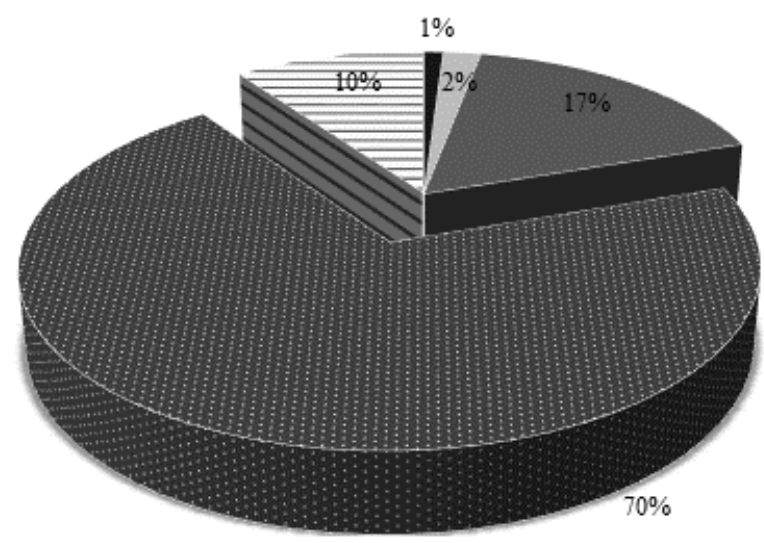

- $<1$ ano $\square 1$ a 4 anos $\mathbf{\square}$ a 19 anos $\mathbf{2 0}$ a 59 anos $=>60$ anos

Figura 4 - Percentual médio (\%) de casos de dengue clássica por faixa etária nos três estados (PR, SC e RS) entre 2001 e 2016. Brasil, 2016

A Figura 5 retrata o número de óbitos ocorridos nas diferentes faixas etárias, por febre hemorrágica devido ao vírus da dengue, nos três estados. Para o ano de 2017, até o mês de novembro não há registro de óbitos devido à dengue hemorrágica (CID A91), conforme informações obtidas nos sites das Secretarias de Saúde do PR e de SC (TABNET) e para o RS em boletins epidemiológicos.

Em se tratando de óbitos por dengue hemorrágica, 72 casos foram registrados no período de 2001 a novembro de 2017. O estado do PR registrou maior número com 67 óbitos (93\%), RS com 4 (5,6\%) e SC com $1(1,4 \%)$.

O estado do PR vem registrando casos de óbitos desde 2003, com maior destaque para 2013, em que registrou 14 óbitos, e em 2016, 20 óbitos (ano com maior notificação de dengue clássica). O RS teve 1 caso em 2001 e 3 casos entre 2015 e 2016, enquanto SC registrou o primeiro caso no primeiro semestre de 2016. Estes dados representam uma realidade bastante preocupante em questão de saúde pública, 
principalmente o estado do PR que liderou no número de óbitos, bem como SC que recentemente registra seu primeiro caso letal, e o RS que registrou aumento nos últimos dois anos. A ausência de registro de óbitos por dengue hemorrágica até novembro de 2017 representa sinais positivos do ponto de vista para a saúde pública.

Conforme figura 5, não houve registro de óbitos em crianças menores de 1 ano para os três estados, porém o PR registrou 7\% dos óbitos em indivíduos entre 5 e 19 anos e 1\% em crianças na faixa etária entre 1 e 5 anos.

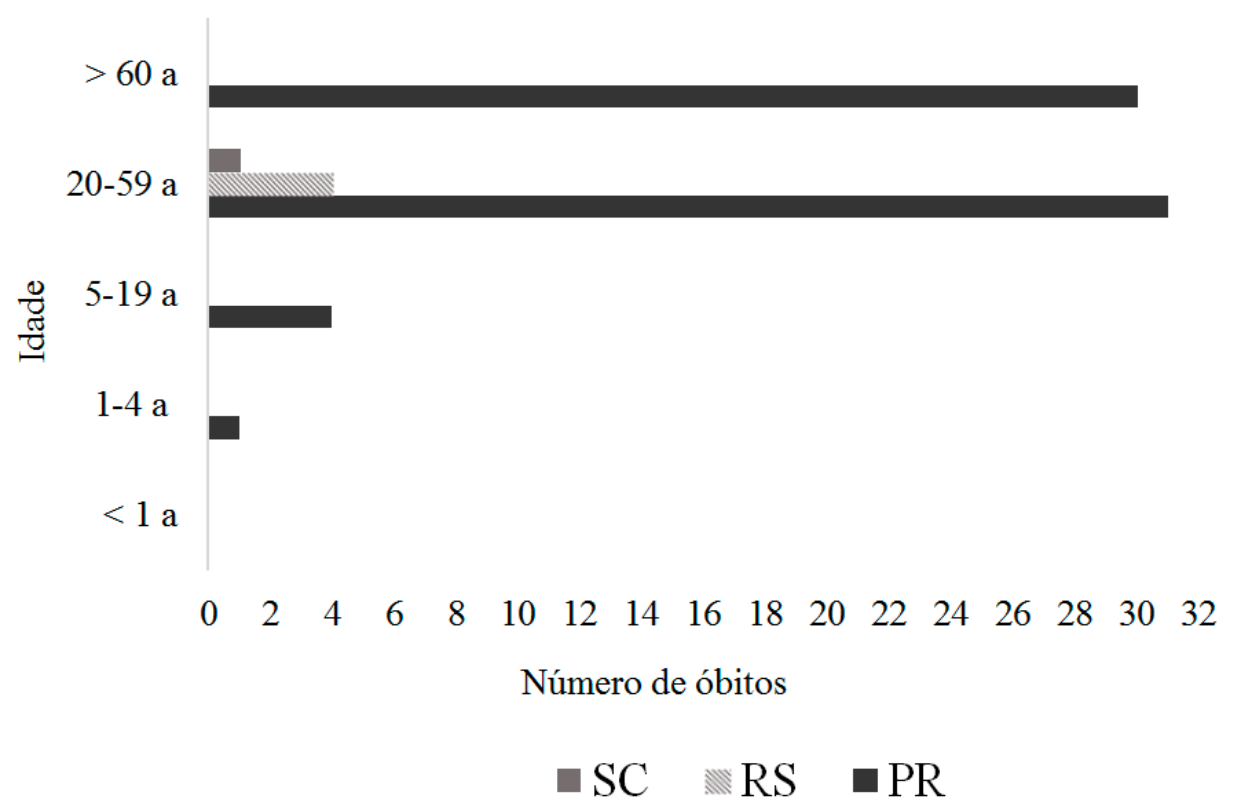

Figura 5 - Número total de óbitos por dengue hemorrágica (CID A91) nas diferentes faixas etárias para PR, SC, RS, entre 2001 e novembro de 2017. Brasil, 2017

\section{DISCUSSÃO}

Na avaliação geral para os três estados e em todo período não houve diferença de acometimento por dengue clássica, sendo igualmente (50\%) para ambos os sexos.

Para o estado do PR, 2013 apresentou maior número de casos notificados, registrando aproximadamente 66 mil casos, colaborando com maior surto ocorrido no Brasil com aproximadamente 2 milhões de notificações. ${ }^{(18)}$ Embora tenha ocorrido uma redução a partir de 2014 em relação ao ano anterior, verifica-se um aumento crescente e gradativo nos últimos três anos, e em 2016 com registro aproximado em 65 mil novos casos, semelhante ao ocorrido em 2013.

Em relação aos estados de SC e RS observou-se aumento para 95\% e 83\%, respectivamente, o registro de casos autóctones nos últimos dois anos. Embora o PR já apresentasse elevado registro autóctone no período 2007 a 2012 (71\%), nos últimos 4 anos evoluiu para 94\% dos casos de transmissão interna. Isto demonstra que os três estados estão contribuindo com aumento de casos de notificação na região. Estes dados parecem apontar para alterações da taxa de casos de dengue na região sul, que detém a menor taxa de notificação no território nacional $(1,2 \%)$, sendo as regiões Nordeste e Sudeste predominantes com 85\% dos casos. ${ }^{(11,19)}$ Por outro lado, em 2017 houve importante redução do número de notificações por dengue clássica, apresentando, respectivamente, queda de 33\%, 41\% e 43\% para PR, RS e SC em relação ao ano de 2016.

O aumento de casos autóctones observados nos três estados contraria a ideia inicial que o clima da região Sul com estações bem definidas e temperatura menor, média anual inferior a $20^{\circ} \mathrm{C}$, em relação às demais regiões com média superior a $20^{\circ} \mathrm{C},{ }^{(20)}$ poderiam ser condições desfavoráveis para a proliferação do vetor, ${ }^{(21)}$ tendo em vista que temperatura inferior a $20^{\circ} \mathrm{C}$ interfere no desenvolvimento e na reprodução do mosquito, levando a uma redução dos casos. ${ }^{(6)}$ 
Determinantes para o aumento crescente, severidade e frequência das epidemias de dengue estão fortemente relacionada com variáveis meteorológicas. Assim, a variação sazonal da temperatura e da pluviosidade influenciam a dinâmica do vetor e a incidência da doença em todo o país, independente do compartimento climático, ${ }^{(3,9)}$ bem como fatores relacionados ao histórico de imunidade, à introdução de novo sorotipo ou às transições demográficas influenciam a transmissão viral. ${ }^{(1)}$

Neste sentido, em território brasileiro, de acordo com informação do Ministério da Saúde, a transmissão vem ocorrendo desde meados de 1986, intercalando-se com a ocorrência de epidemias, frequentemente associadas com a introdução de novos sorotipos em áreas anteriormente indenes ou alteração do sorotipo predominante. ${ }^{(18)}$

Na região sul do país todas as faixas etárias foram acometidas, embora em percentuais diferentes. Enquanto na região sul, no Brasil e também em regiões da América, indivíduos adultos são predominantemente afetados, ${ }^{(21)}$ em outras regiões do mundo como no sudeste asiático a dengue atinge principalmente crianças. ${ }^{(22)}$

Além disto, no estado do RJ durante epidemia em 2007, foi descrita uma mudança na distribuição etária da dengue, com aumento de casos em crianças. ${ }^{(23)}$ No entanto, neste período avaliado, não se observou aumento de dengue em crianças na região sul.

Com isso, na tentativa de reduzir a disseminação da doença e seus agravantes, recentes notícias de veiculação nacional destacam o estado do PR, pioneiro no país, a realizar desde o segundo semestre de 2016, campanha de vacinação pública contra dengue em alguns municípios do estado. A introdução da vacinação poderá ser um forte aliado no combate à doença, bem como poderá reduzir o impacto na saúde pública em localidades onde a doença é endêmica. ${ }^{(25)}$ Embora, medidas de controle do vetor com a participação dos cidadãos e do poder público devam permanecer constantes como alternativas de redução e disseminação da doença.

A fim de estimar os impactos da vacinação, pesquisadores conduziram um estudo no qual utilizaram diferentes dados de países endêmicos do continente asiático e latino-americano e observaram reduções significativas, após a introdução da vacina, nos casos de dengue na população durante os primeiros 10 anos. $^{(25)}$

Neste contexto, estudos futuros devem ser realizados a fim de fornecer dados em relação aos impactos pós-vacinação, em diferentes populações e regiões onde a vacinação for introduzida, embora a vacina já tenha demonstrado segurança e imunogenicidade satisfatórias em testes pré-clínicos in vitro e in vivo e em estudos clínicos. ${ }^{(26)}$

Após longo período de pesquisas, somente a partir do segundo semestre de 2016 a primeira vacina tetravalente foi aprovada e liberada no Brasil e em nível mundial, na qual encontra-se em fase de implantação e, portanto, não há ainda alguma resposta satisfatória quanto aos efetivos impactos na saúde pública.

É importante destacar a ausência de informações (de casos autóctones) na base de dados do DATASUS ${ }^{(13)}$ no período de 2001 a 2006. Sendo assim, a ausência de informação foi um fator limitante no sentido de que o estudo poderia avaliar um período mais extenso e com dados mais representativos. Não foi possível avaliar casos de dengue no período anterior a 2001, pois não há registro, conforme busca realizada na plataforma do DATASUS. ${ }^{(13)}$

Mesmo assim, podemos verificar um avanço do sistema de informação a partir do ano de 2007, em que se verifica melhor a organização e disponibilidade de dados, embora ainda haja fatores a serem melhorados, principalmente no que tange à alimentação de dados de forma mais rápida e constante.

De modo geral, houve dificuldade em encontrar a mesma informação (quantificação exata) nas diferentes bases pesquisadas, principalmente nas informações que se referem à dengue clássica. Sendo assim, este estudo revela a necessidade de aprimoramento e implantação de sistema de informação único, que possa fornecer informação atualizada e consistente, sem a necessidade de realizar diferentes buscas dentro das bases atualmente disponíveis, as quais demandam tempo e apresentam, muitas vezes, inconsistência de informação. 
Além disto, no atual sistema de informação (DATASUS/SINAN) não é possível identificar o sorotipo viral (DENV 1, 2, 3, 4), informação relevante para saúde pública e estudos de pesquisa. A inserção desta informação poderá auxiliar no monitoramento dos tipos virais que estão circulando em determinadas regiões, bem como o surgimento de novos sorotipos, e, consequentemente obter-se um rastreamento da evolução dos diferentes tipos virais da dengue em cada região.

No geral, os casos de óbitos no sul do Brasil ocorreram em indivíduos de ambos os sexos com maior frequência para o sexo feminino (54\%), semelhante ao estudo epidemiológico do estado de São Paulo, ${ }^{(27)}$ bem como no RS todos os óbitos ocorridos (100\%) pertenceram ao sexo feminino. A faixa etária com maior ocorrência de óbitos foi em adultos entre 20 e 59 anos (50\%) e superior a 60 anos $(42 \%)$, totalizando mais de $90 \%$ dos óbitos em adultos, concordando com dados de dengue clássica anteriormente citados. Registros de casos de óbitos desta região assemelham-se com dados nacionais, onde a incidência de Febre hemorrágica (FHD) e com complicações (DCC), que são fatores de risco para óbito, tem sido maior em adultos. ${ }^{(23)}$

A ausência de registro de óbito em criança menor de 1 ano nos três estados é um sinal positivo do ponto de vista de saúde pública, embora o PR tenha registrado, em 2014, seu primeiro óbito em criança entre 1 e 5 anos, e 5 óbitos entre 5 e 19 anos de idade, a partir de 2007.

A ocorrência de óbitos por dengue no período da infância e adolescência também foi observada no estado de São Paulo, ${ }^{(27)}$ onde até o ano de 2007 não havia registro de óbitos em indivíduos menores que 15 anos. A partir de 2008 teve uma média aproximada de 13\%, sendo em 2010 o primeiro óbito em criança menor de 1 ano, no referido estado.

Em 2008, o estado do RJ apresentou situações de gravidade por dengue em faixa etária menor. Apesar da população de 15-49 anos ter apresentado maior número de notificações (54\%), foi em indivíduos de 0 a 15 anos que apresentaram maior gravidade da doença, representando $48 \%$ das notificações e internações e $42 \%$ dos óbitos. ${ }^{(28)}$ Assim, estes dados revelam sinais de alerta para o aumento de casos letais nestas novas faixas etárias, bem como trazem referência do crescente aumento de óbitos por dengue na região sul, especialmente no estado do PR.

A dengue possui uma vasta gama de apresentações clínicas, e não há uma relação clara e evidente que relacione se determinado sorotipo viral possa desencadear a dengue clássica ou febre hemorrágica, ou algum sintoma específico que reporte um determinado sorotipo. Evidências sugerem que os anticorpos neutralizantes e as reações cruzadas regulam as epidemias de dengue e a gravidade da doença. ${ }^{(2,22)}$

Assim, estudo realizado em países latino-americanos (últimas três décadas) sugere que uma infecção anterior poderá definir o cenário para uma infecção mais grave por um sorotipo diferente em situações posteriores. ${ }^{(29)}$ Deste modo, a mortalidade por dengue, conforme a OMS, pode ser reduzida através da implementação da gestão clínica apropriada, diagnóstico laboratorial e manejo clínico adequado, capacitação de recursos humanos em todos os níveis do sistema de saúde e reorganização hospitalar.(3)

\section{CONCLUSÕES}

Este estudo contribuiu com o conhecimento da ocorrência e evolução de dengue clássica e hemorrágica na região sul do Brasil, tendo em vista que há escassez de estudos publicados sobre o tema desta região do país.

Este levantamento mostrou crescente aumento de registro de casos autóctones nos três estados, principalmente nos últimos anos (ano de 2017 não incluso), enfatizando que a região se encontra em situação de alerta e necessita tomar medidas de controle sanitárias e ambientais mais eficazes no combate ao vetor.

Aumento de notificações por dengue clássica, principalmente nos últimos anos, PR a partir de 2013, SC e RS a partir de 2015, reforçam a necessidade de controle rigoroso do vetor e estratégias de redução da doença nesta região. 
O crescente aumento de óbitos por dengue hemorrágica, principalmente no estado do PR, o registro do primeiro óbito em SC e o aumento nos últimos anos no RS requer atenção dos órgãos em saúde. Há esforços constantes, porém são insuficientes e estão permitindo o aumento de casos graves e letais também na região sul, embora até novembro de 2017 não tenha havido registros de óbitos desta natureza.

O estudo mostrou que é necessario melhorias no sistema de informação (DATASUS/SINAN), em que se sugere a implantação de uma única plataforma com informações de mortalidade e morbidade por dengue, delimitada por estado. Além disto, faz-se necessario a inclusão de dados dos sorotipos virais (DENV 1, 2, 3, 4) e redução do tempo na alimentação das informações na plataforma de acesso.

\section{REFERÊNCIAS}

1. World Healt Organization (WHO). Dengue guidelines for diagnosis, treatment, prevention and control (new edition) 2009. [Internet] WHO; 2009 [acesso em 10 dez 2016]. Disponível: http://whqlibdoc.who.int/ publications/2009/9789241547871_eng.pdf.

2. World Healt Organization (WHO). Dengue. [internet] [acesso em 10 dez 2016]. Disponível: http://www.who.int/ topics/dengue/em/.

3. World Healt Organization (WHO). Global strategy for dengue prevention and control 2012-2020. [Internet] WHO; 2012 [acesso em 10 dez 2016]. Disponível: http://apps.who.int/iris/bitstream/10665/75303/1/9789241504034_eng.pdf.

4. Bhatt S, Gething PW, Brady OJ, Messina JP, Farlow AW, Moyes CL et al. The global distribution and burden of dengue. Nature. [internet] 2013;496(7446) [acesso em 26 dez 2016]. Disponível: http://dx.doi:10.1038/nature12060.

5. Shepard DS, Coudeville L, Halasa YA, Zambrano B, Dayan GH. Economic impact of Dengue Illness in the Americas. Am J Trop Med Hyg. [Internet] 2011;84(2) [acesso em 20 dez 2016]. Disponível: https://doi.org/10.4269/ ajtmh.2011.10-0503.

6. Instituto Osvaldo Cruz (IOC/FIOCRUZ). Dengue Vírus e Vetor - Longa Trajetória. [Internet] IOC/FIOCRUZ [acesso em 10 jan 2017]. Disponível: http://www.ioc.fiocruz.br/dengue/textos/longatraje.html.

7. Osanai CH, Rosa AP, Tang AT, Amaral RS, Passos AD, Tauil PL. Surto de dengue em Boa Vista, Roraima. Rev Inst Med trop São Paulo. [Internet] 1983;25(1) [acesso 28 dez 2016]. Disponível: http://www.imt.usp.br/wp-content/uploads/ revista/vol25/53-54.pdf.

8. Organização Pan-Americana da Saúde (OPAS). Ministério da Saúde, Série Saúde Ambiental 3. Mudança Climática e Saúde: um perfil do Brasil. [Internet] Brasília: OPAS; 2009 [acesso em 10 dez 2016]. Disponível: http://bvsms.saude. gov.br/bvs/publicacoes/mudanca_climatica_saude.pdf.

9. Viana DV, Ignotti E. A ocorrência da dengue e variações meteorológicas no Brasil: revisão sistemática. Rev. bras. epidemiol. [Internet] 2013;16(2) [acesso em 25 jan 2017]. Disponível: http://dx.doi.org/10.1590/S1415$790 \times 2013000200002$.

10. Guha-Sapir D, Schimmer B. Dengue fever: new paradigms for a changing epidemiology. Emerg Themes Epidemiol. [Internet] 2005;2(1) [acesso em 10 jan 2016]. Disponível: https://doi.org/10.1186/1742-7622-2-1.

11. Bõhm AW, Costa CS, Neves RG, Flores TR, Nunes BP. Tendência da incidência de dengue no Brasil, 20022012. Epidemiol. Serv. Saúde. [Internet] 2016;25(4) [acesso 20 dez 2016]. Disponível: http://www.scielo.br/scielo. php?pid=S2237-96222016000400725\&script=sci_abstract\&tlng=pt.

12. Ministério da Saúde (BR). Portal Saúde SUS. Situação epidemiológica. Casos de Dengue - Brasil, Grandes Regiões e Unidades Federadas, 1990 a 2016. [internet] [acesso em 01 set 2016]. Disponível: http://portalarquivos2.saude.gov.br/ images/pdf/2017/fevereiro/10/Dengue-classica-ate-2016.pdf.

13. Ministério da Saúde (BR). Departamento de Informática do Sistema Único de Saúde (DATASUS). Portal de saúde SUS - Informações de Saúde (TABNET) - Epidemiológicas e Morbidade. [Internet] [acesso em 28 nov 2017]. Disponível: http://www2.datasus.gov.br/DATASUS/index.php?area=0203. 
14. Paraná. Governo do Estado do Paraná. Secretaria da Saúde. Boletim da Dengue. Situação da dengue, chikungunya e zika vírus no Paraná [internet] [acesso em 28 nov 2017]. Disponível: http://www.dengue.pr.gov.br/.

15. Governo do Estado de Santa Catarina. Secretaria do estado de Saúde de Santa Catarina. Dengue, zika e chikungunya. Boletim. [Internet] [acesso em 28 nov 2017]. Disponível: http://www.dengue.sc.gov.br/.

16. Governo do Estado do Rio Grande do Sul. Secretaria da Saúde. Informativo Epidemiológico dengue, chikungunya e zika vírus. [Internet] [acesso em 28 nov 2017]. Disponível: http://www.cevs.rs.gov.br/dengue-chikungunya-zika-virus.

17. Ministério da Saúde (BR). Departamento de Informática do Sistema Único de Saúde (DATASUS). Tecnologia de informação a serviço do SUS. Mortalidade Brasil. [internet] 2016 [acesso em 28 nov 2017]. Disponível: http://tabnet. datasus.gov.br/cgi/deftohtm.exe?sim/cnv/obt10uf.def.

18. Ministério da Saúde (BR). Portal da Saúde SUS. Dengue. Descrição da doença. [Internet] [acesso em 28 nov 2017 ]. Disponível: http://portalms.saude.gov.br/saude-de-a-z/dengue/descricao-da-doenca.

19. Câmara FP, Theophilo RLG, dos Santos GT, Pereira SRFG, Câmara DCP, de Matos RRC. Estudo retrospectivo (histórico) da dengue no Brasil: características regionais e dinâmicas. Rev. Soc. Bras. Med. Trop. [Internet] 2007;40(2) [acesso em 10 jan 2017]. Disponível: http://dx.doi.org/10.1590/S0037-86822007000200009.

20. Instituo Nacional de Meteorologia (INMET). Ministério da Agricultura, Pecuária e Abastecimento. Temperatura média anual. [Internet] [acesso em 10 jan 2017]. Disponível: http://www.inmet.gov.br/portal/.

21. Teixeira MG, Costa MCN, Barreto ML, Mota E. Dengue and dengue hemorrhagic fever epidemics in Brazil: what research is needed based on trends, surveillance, and control experiences? Cad. Saúde Pública. [Internet] 2005;21(5) [acesso em 09 jan 2017]. Disponível: http://dx.doi.org/10.1590/S0102-311X2005000500002.

22. Halstead SB. Dengue in the Americas and Southeast Asia: do they differ? Rev Panam Salud Publica. [Internet] 2006;20(6) [acesso em 09 jan 2017]. Disponível: http://www.scielosp.org/pdf/rpsp/v20n6/a07v20n6.pdf.

23. Siqueira JB, Vinhal LC, Said RFC, Hoffmann JL, Martins J, Barbiratto SB et al. Dengue no Brasil: tendências e mudanças na epidemiologia, com ênfase nas epidemias de 2008 e 2010. In: Ministério da Saúde. Saúde Brasil 2010: uma análise da situação de saúde e de evidências selecionadas de impacto de ações de vigilância em saúde. Brasília: Ministério da Saúde; 2011. p. 157 - 171. Disponível: http://bvsms.saude.gov.br/bvs/publicacoes/saude_brasil_2010.pdf.

24. Pan ST, Su PA, Chen KT, Lin HJ, Lai WP. Comparison of the clinical manifestations exhibited by dengue and nondengue patients among children in a medical center in southern Taiwan. JACME. [Internet] 2014;4(2) [acesso 10 dez 2016]. Disponível: https://doi.org/10.1016/j.jacme.2013.10.007.

25. Coudeville L, Baurin N, L'azou M, Guy B. Potential impact of dengue vaccination: Insights from two large-scale phase III trials with a tetravalent dengue vaccine. Vaccine. [Internet] 2016;34(50) [acesso em 20 dez 2016]. Disponível: http://dx.doi.org 10.1016/j.vaccine.2016.08.050.

26. Guy B, Barrere B, Malinowski C, Saville M, Teyssour R, Lang J. From research to phase III: preclinical, industrial and clinical development of the sanofi Pasteur tetravalent dengue vaccine. Vaccine. [Internet] 2011;29(42) [acesso em 20 dez 2016]. Disponível: https://doi.org/10.1016/j.vaccine.2011.06.094.

27. Souza PB. Perfil epidemiológico dos casos graves de dengue no estado de São Paulo, 1998 a 2010. [Dissertação]. São Paulo (SP): Faculdade de Ciências Médicas da Santa Casa de São Paulo; 2013.

28. Governo do estado do Rio de Janeiro. Secretaria de Estado de Saúde e Defesa Civil. Relatório de casos de dengue2008. Rio de Janeiro, 2008 [acesso em 10 dez 2016]. Disponível: http://www.cives.ufrj.br/informacao/dengue/ses/ Relat\%C3\%B3rio\%20de\%20Casos\%20de\%20Dengue\%20_15-05-2008\%20-\%2016h30m_.pdf .

29. San Matín JL, Brathwaite O, Zambrano B, Solórzano JO, Bouckenooghe A, Dayan GH et al. The epidemiology of dengue in the Americas Over the last three decades: a worrisome reality. Am. J. Trop. Med. Hyg. [Internet] 2010;82(1) [acesso em 20 dez 2016]. Disponível: https://doi.org/10.4269/ajtmh.2010.09-0346. 